\title{
Stochastic beach profile modelling
}

\author{
KD Seddon ATC Williams Pty Ltd, Australia \\ B Pirouz ATC Williams Pty Ltd, Australia \\ TG Fitton Fitton Tailings Consultants, Australia
}

\begin{abstract}
Modelling of a tailings beach using a time series of thickener output (flow rate and solids concentration) was first reported by Fitton et al. (2007). Seddon and Fitton (2011) presented statistical data on the performance of thickeners, and showed that the observed concave shape in tailings beaches could be adequately explained by this variability. They then proposed a stochastic method for the generalised modelling of tailings beaches. The aim of this paper is to demonstrate the application and results obtained by the use of this method.
\end{abstract}

This paper shows how thickener performance statistics in the form of frequency functions for variations in (a) underflow solids concentration; and (b) mass flow rate, can be combined with a set of rheology results to develop a predictive beach slope distribution. Data developed from this distribution are then used as an input to a deposition modelling program. The developed beach profile is presented for a typical case.

\section{Introduction}

One of the central concepts of the thickened discharge system is that discharge of thickened tailings will result in a consistent beach slope (Robinsky 1999). The implication is that for a constant flow rate and slurry density (or strictly, for constant slurry rheology), tailings will form a uniform planar beach slope down the full length of the beach.

In practice, beach profiles with a degree of concavity are commonly encountered for thickened tailings beaches. A number of theories have been put forward to account for this. Theories that depend on selective deposition based on particle size or segregation are generally not applicable, as segregation does not occur for the majority of thickened tailings slurries (e.g. Seddon \& Albee 2015). Other theories attempt to relate concavity to shear thinning as the slurry flows down the beach. This approach may have some application in the case of highly flocculated slurries resulting from in-line flocculation, for which studies have shown significant rheological breakdown on shearing (Slatter \& Seddon 2015). However for thickened tailings slurries that have been subjected to centrifugal pumping, the fundamental rheology can be considered to be due to the presence of the fine tailings particles, and not to the presence of flocculants. As an example, Pirouz et al. (2013) present results from a pilot plant trial in which the rheology of the circulating tailings remained constant for periods of days.

Seddon and Fitton (2011) proposed that concave beach profiles can be attributed to the fact that tailings properties and discharge rates do not stay constant over a period of time. Cumulative distribution curves for (a) thickener underflow solids concentration, and (b) mass flow rate, were presented by Seddon and Fitton (2011), who then utilised this data in an approximate method to demonstrate the development of beach concavity.

The authors also outlined a more rigorous design methodology utilising a stochastic approach to predict beach slope as a part of a time series, and to model the subsequent build-up of the beach using a short time step input into a tailings deposition type program.

This paper provides further details and an example of this proposed approach. 


\section{Background}

The first numerical modelling of a concave beach was reported by Fitton et al. (2007), who showed that an observed concave beach slopes profile could be adequately modelled by explicitly replicating the relevant parameters (flow and rheology) in a stepwise daily deposition model. This was a significant result, as it provided confirmation of the reasons for the observed beach concavity. However, given that it involved an analysis of historical data to replicate the performance of a beach that already existed, it did not provide a method that could be used directly for forecasting and design purposes.

This was addressed by Seddon and Fitton (2011) with the proposal that thickener performance could be evaluated on a statistical basis. The beach slope comparisons reported by Seddon and Fitton (2011) were still based on analysis of historical data (for comparison with historically recorded beach slopes). But they recognised that for the purposes of design, it was possible to select key statistical variables, and from these and the project data, develop design curves.

\section{$3 \quad$ Methodology}

The methodology adopted in this paper is an extension of that proposed by Seddon and Fitton (2011). The basic steps in the process are:

- Establish or select statistical distributions (cumulative curves) for the key parameters of throughput (tonnes) and solids concentration.

- Convert solids concentration to equivalent slurry rheology.

- Calculate volumetric flow rate equivalent to each combination of mass throughput and solids concentration.

- Select an appropriate method (or methods) of beach slope prediction, and calculate the beach slope for each combination, hence develop a predictive (cumulative) frequency curve for beach slope.

- Using available deposition software (either 'in-house' or a commercial package) model the build-up of the beach in a step-wise manner, with incremental data generated from the beach slope frequency curve.

Details of this approach are shown in the example following. It should be noted that for the example a daily time increment is adopted, but other durations could be used.

\section{$4 \quad$ Thickener performance characteristics}

\subsection{General}

Seddon and Fitton (2011) used the statistics of (cumulative) normal distributions to characterise thickener performance, and presented data for five sites. Data on thickener performance is now available for additional sites, and has been analysed for the purpose of selecting 'representative' values for inclusion in the analysis. A separate paper is envisaged to present and discuss these results in more detail, in due course.

Nevertheless, it is noted that the database of thickener performance curves is still limited, and this is an area that may warrant further data collection.

Normal distributions are formulated in terms of a mean and a standard deviation. For comparing the spread or variability over different distributions, the coefficient of variability (CV) is used, where $\mathrm{CV}=$ standard deviation/mean. This is effectively a 'normalised' parameter, which is independent of the magnitude of the values which are incorporated in the mean and standard deviation terms. 
The normal distribution curves presented by Seddon and Fitton (2011) provided a reasonable fit for solids concentration, but is was recognised that the data for (mass) flow of solids was asymmetrical, and the normal distribution did not provide a particularly good fit. The availability of subsequent data sets has supported this. It would be possible to fit a different mathematical distribution to these data (i.e. one incorporating a skewed distribution). However for present purposes an approach based on a 'two-tailed' normal distribution has been adopted. This uses the same mean value for the upper and lower distributions, but a larger standard deviation for the more skewed lower data, as shown later in this paper.

Finally it should be noted that the method demonstrated herein assumes that the underflow solids concentration is independent of the mass flow rate. This has been checked for some (but not all) of the available data sets, and shown to be a reasonable assumption.

It would be possible to adapt the currently proposed methodology to account for a degree of cross-correlation if this was found to exist, but this would make the statistics more complex.

\subsection{Solids concentration}

For the variability of underflow solids concentration, Seddon and Fitton (2011) reported values of CV in the range $0.025-0.08$, and adopted a value of 0.05 for their reported analysis. Incorporation of the additional thickener data has not changed this assessment, which is still considered to be a reasonable estimate for a well operated thickener. Consequently solids concentration variability has been analysed for a $\mathrm{CV}=0.05$.

\subsection{Mass flow rate}

For characterisation of mass flow rate, Seddon and Fitton (2011) reported values of CV in the range $0.12-0.19$, noting that this was based on the use of a symmetrical distribution.

In this paper the calculation has been based on an asymmetrical distribution using $\mathrm{CV}=0.07$ for the top, and $\mathrm{CV}=0.12$ for the bottom of the range. On the basis of previous data this may be considered to be representative of 'good' thickener operations.

\section{$5 \quad$ Design example}

\subsection{Basic parameters}

An example case has been fabricated to illustrate the proposed method. The basic (assumed) parameters are shown in Table 1.

\section{Table 1 Basic parameters of example operation}

\begin{tabular}{ccc}
\hline Parameter & Unit & Quantity \\
\hline Nominal plant throughput & Mtpa (dry) & 10 \\
Annual operating hours & $\mathrm{h}$ & 8,000 \\
Solids particle density (SG) & $\mathrm{t} / \mathrm{m}^{3}$ & 2.65 \\
In situ density (dry), end of filling & $\left(\mathrm{t} / \mathrm{m}^{3}\right)$ & 1.50 \\
Nominal daily throughput & $\mathrm{t} / \mathrm{day}$ & 30,000 \\
Nominal daily volume increment & $\left(\mathrm{m}^{3}\right)$ & 20,000 \\
\hline
\end{tabular}




\subsection{Selection of operating characteristics}

\subsubsection{Solids concentration}

It is assumed that the thickener and associated pumping and pipeline system for the underflow have been sized to produce and handle a 'maximum' underflow solids concentration of $66 \%$. There is a degree of uncertainty as to where this point should be located on the distribution curve. For the purposes of this exercise it has been set at the P85 point (nominally equal to the mean plus $1 \times$ standard deviation (SD)).

Hence for $\mathrm{CV}=0.05$ we obtain:

Mean: 62.8.

$\mathrm{SD}: \quad 3.14(=0.05 \times 62.8)$.

P85: $\quad($ mean $+1 \times S D)=62.8+3.14=65.94$, approximately equal to the design maximum value.

The resulting cumulative frequency curve is shown in Figure 1.

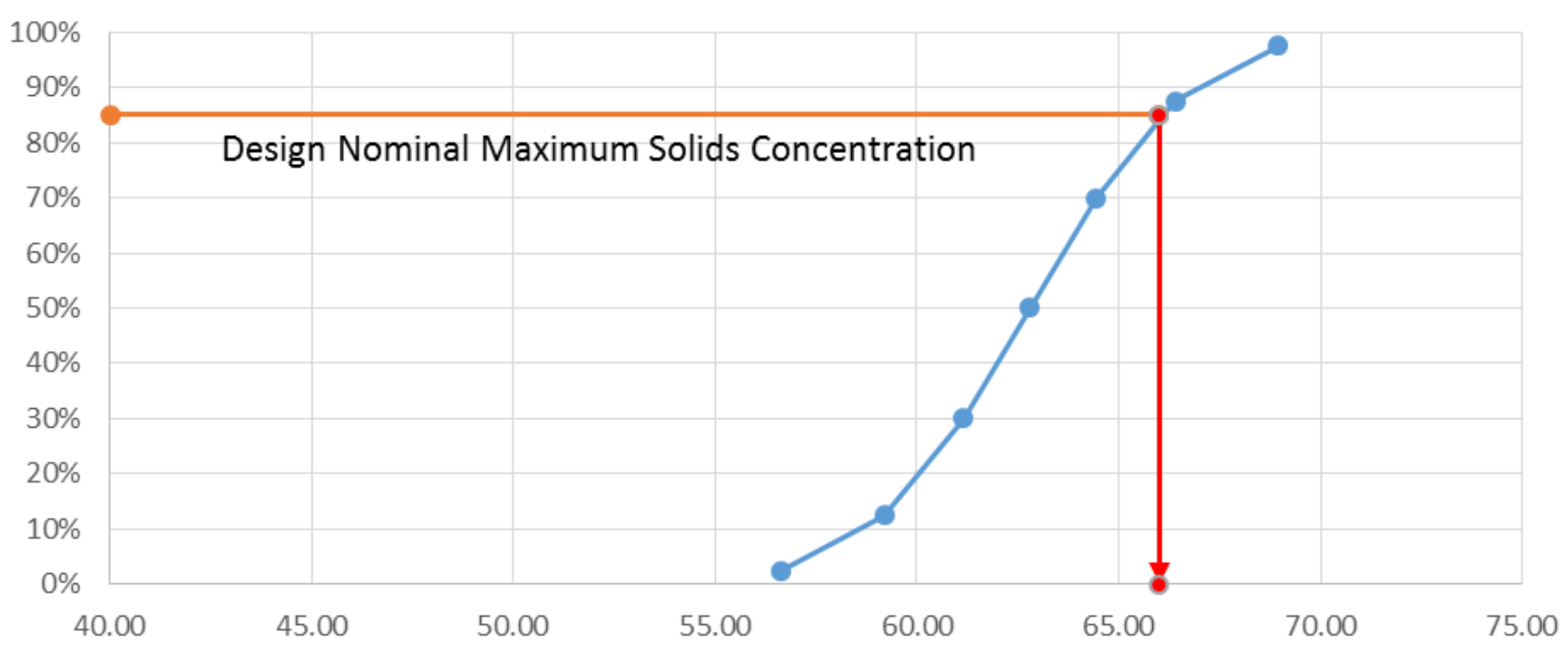

Figure 1 Derived cumulative probability curve for underflow solids concentration

\subsubsection{Mass flow rate}

For the nominal daily throughput of $30,000 \mathrm{t} /$ day, the equivalent hourly value is $1,250 \mathrm{t} / \mathrm{h}$. For the purposes of this exercise this has been taken to be the mean value. As discussed in Section 4.3, an asymmetric distribution has been modelled based on $C V=0.07$ for the upper half, and $C V=0.12$ for the lower half.

Hence we obtain:

Mean: $\quad 1,250 \mathrm{t} / \mathrm{h}$.

SD (upper): $\quad 87.5(=0.07 \times 1,250)$.

SD (lower): $\quad 150(=0.12 \times 1,250)$.

This produces the asymmetrical distribution shown in Figure 2. 


\section{Mass Flow Rate}

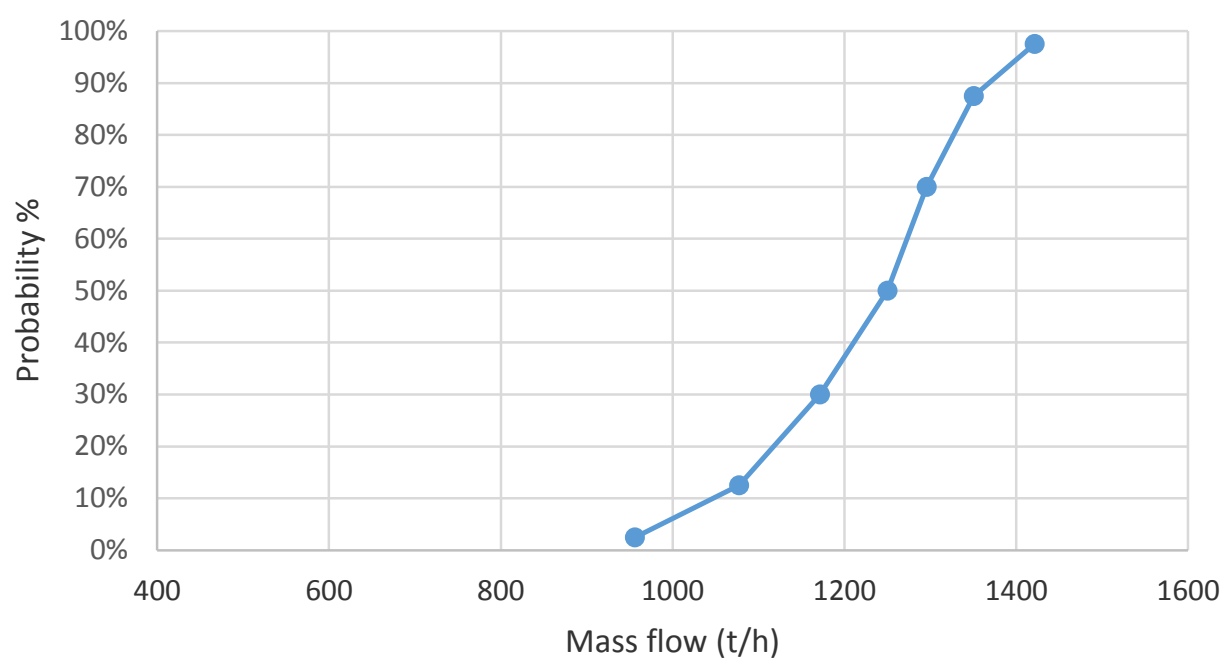

Figure 2 Derived cumulative probability curve for mass flow rate

\subsubsection{Slurry rheology}

It must be emphasised here that while the while the thickener performance data are presented in terms of underflow solids concentration, the method requires data for slurry rheology for the range of solids that need to be considered in the design process. In is noted that for a well instrumented thickener, monitoring and recording of values that could enable statistical distributions of rheology to be assembled directly should be possible. However in practice it is common to monitor underflow density, and not rheology, and to date no direct monitoring for rheology is available.

For the purposes of this paper, a real data set of slurry rheology has been extracted from a previous project. The results are shown in Figure 3. Interpolation (and a small degree of extrapolation) of these results provides input rheology parameters for all the necessary categories. It should be noted that the rheology data shows significant increases above about $66 \%$ solids.

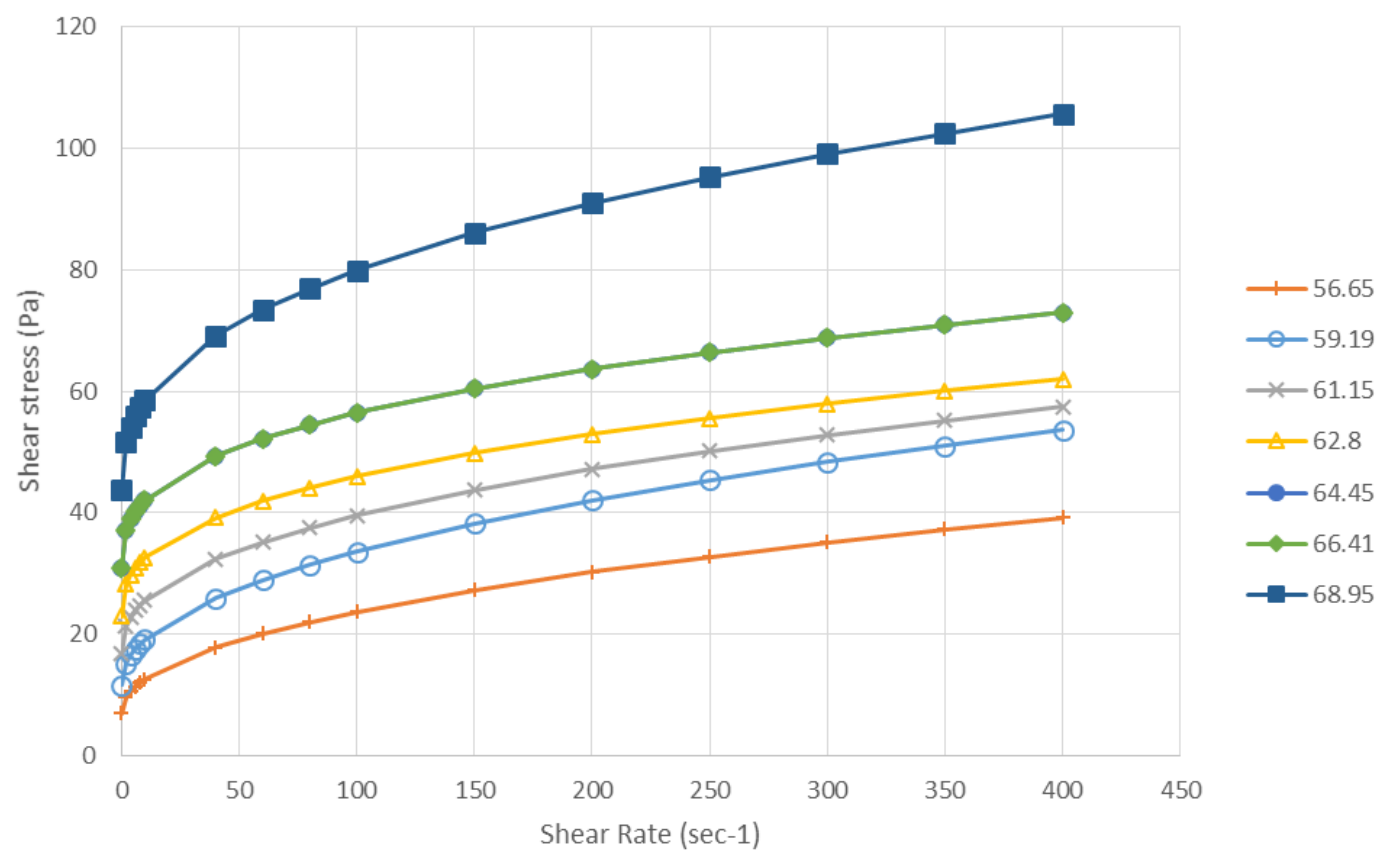

Figure 3 Adopted rheology curves 
It should also be noted that this approach assumes that rheology is dependent only on the value of the underflow solids, i.e. that the ore fed to the process is uniform throughout the modelling period. There are many operations where this assumption could be regarded as unrealistic, and allowances for variations in ore/slurry rheology may need to be incorporated into the process.

\subsection{Probability matrix}

To facilitate calculations, the cumulative distributions of solids concentration (Figure 1) and mass flow rate (Figure 2) have each been portioned into seven groups, resulting in a $7 \times 7$ probability matrix for all the considered combinations of flow and concentration/rheology, as shown in Table 2. The selected group ranges are not equal, to give better definition of the extreme ends of the distribution curves. It is noted that the number of groups could be increased, and this would improve definition of the extremes.

It is also noted that for the purposes of subsequent calculations the value of mass flow or solids concentration equal to the mid-point of each range has been adopted, as shown in Table 2 .

Table 2 Derivation of joint probabilities of considered combinations

\begin{tabular}{ccc}
\hline \multicolumn{3}{c}{ Solids concentration } \\
\hline $\begin{array}{c}\text { Range } \\
(\%)\end{array}$ & $\begin{array}{c}\text { Group } \\
\text { probability }\end{array}$ & $\begin{array}{c}\text { Range } \\
\text { value } \\
\text { (solids \%) }\end{array}$ \\
\hline $100-95$ & 0.05 & 56.65 \\
$95-80$ & 0.15 & 59.19 \\
$80-60$ & 0.2 & 61.15 \\
$60-40$ & 0.2 & 62.8 \\
$40-20$ & 0.2 & 64.45 \\
$20-5$ & 0.15 & 66.41 \\
$5-0$ & 0.05 & 68.95 \\
\hline
\end{tabular}

\begin{tabular}{ccccccc}
\hline \multicolumn{7}{c}{ Mass flow } \\
\hline \multicolumn{7}{c}{ Range (\%) } \\
\hline $100-95$ & $95-80$ & $80-60$ & $60-40$ & $40-20$ & $20-5$ & $5-0$ \\
\hline \multicolumn{7}{c}{ Group probability } \\
\hline 0.05 & 0.15 & 0.2 & 0.2 & 0.2 & 0.15 & 0.05 \\
\hline \multicolumn{7}{c}{ Range value (t/s) } \\
\hline 0.39 & 0.38 & 0.36 & 0.35 & 0.33 & 0.3 & 0.27 \\
\hline \multicolumn{7}{c}{ Joint probability } \\
\hline 0.0025 & 0.0075 & 0.01 & 0.01 & 0.01 & 0.0075 & 0.0025 \\
0.0075 & 0.0225 & 0.03 & 0.03 & 0.03 & 0.0225 & 0.0075 \\
0.01 & 0.03 & 0.04 & 0.04 & 0.04 & 0.03 & 0.01 \\
0.01 & 0.03 & 0.04 & 0.04 & 0.04 & 0.03 & 0.01 \\
0.01 & 0.03 & 0.04 & 0.04 & 0.04 & 0.03 & 0.01 \\
0.0075 & 0.0225 & 0.03 & 0.03 & 0.03 & 0.0225 & 0.0075 \\
0.0025 & 0.0075 & 0.01 & 0.01 & 0.01 & 0.0075 & 0.0025 \\
\hline
\end{tabular}

\subsection{Beach slope calculation}

The proposed methodology is not specific to any of the range of methods of beach slope prediction now available. It does however imply that prediction methods should be based on the overall 'channel geomorphology' paradigm, and recognise the effects of the principal variants of rheology and slurry flow rate on the resulting calculated beach slope. Methods that fit within this framework but also require other input parameters (e.g. particle size distribution) should adopt mean values for these parameters.

The next required step is to combine the range values for both mass flow rate and solids concentration to obtain the volumetric flow rate for each considered combination (Table 3). 
Table 3 Derivation of volumetric flow rate

\begin{tabular}{|c|c|c|c|c|c|c|c|}
\hline \multirow{3}{*}{$\begin{array}{c}\text { Solids } \\
\text { concentration } \\
\text { (\%) }\end{array}$} & \multicolumn{7}{|c|}{ Mass flow rate $t / s$} \\
\hline & 0.39 & 0.38 & 0.36 & 0.35 & 0.33 & 0.3 & 0.27 \\
\hline & \multicolumn{7}{|c|}{ Volumetric flow rate $(\mathrm{L} / \mathrm{s})$} \\
\hline 56.65 & 451 & 429 & 411 & 397 & 372 & 342 & 303 \\
\hline 59.19 & 421 & 400 & 384 & 370 & 347 & 319 & 283 \\
\hline 61.15 & 400 & 380 & 365 & 352 & 329 & 303 & 269 \\
\hline 62.8 & 383 & 364 & 349 & 337 & 316 & 290 & 258 \\
\hline 64.45 & 367 & 349 & 334 & 323 & 302 & 278 & 247 \\
\hline 66.41 & 349 & 331 & 318 & 307 & 287 & 264 & 235 \\
\hline 68.95 & 327 & 310 & 298 & 287 & 269 & 248 & 220 \\
\hline
\end{tabular}

For each of the $49(7 \times 7)$ considered cases, the beach slope is then calculated using:

- volumetric flow rates (Table 3); and

- rheology (interpolated from Figure 3) for each of the solids concentration ranges.

For this exercise, the method of Pirouz et al. (2014) has been used, but as noted above, any compatible method can be used. Utilisation of a number of different methods using this overall approach and comparing the resulting profiles is a subject for further study.

The results of these calculations are shown in Table 4. This indicates a maximum expected beach slope of $2.5 \%$ (for the highest rheology and lowest flow rate), ranging down to a minimum slope of $0.58 \%$ (for the lowest rheology and highest flow rate). Consideration of a greater number of groups would extend this range.

Table 4 Results of beach slope calculation

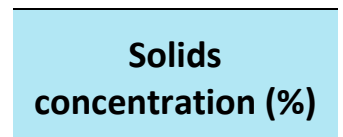

56.65

59.19

61.15

62.8

64.45

66.41

68.95

\begin{tabular}{ccccccc}
\hline \multicolumn{7}{c}{ Mass flow rate (t/s) } \\
\hline 0.39 & 0.38 & 0.36 & 0.35 & 0.33 & 0.3 & 0.27 \\
\hline \multicolumn{7}{c}{ Beach slope (\%) } \\
\hline 0.58 & 0.6 & 0.61 & 0.62 & 0.64 & 0.67 & 0.71 \\
0.73 & 0.75 & 0.77 & 0.78 & 0.81 & 0.84 & 0.9 \\
1.02 & 1.05 & 1.07 & 1.09 & 1.13 & 1.18 & 1.25 \\
1.2 & 1.24 & 1.26 & 1.29 & 1.33 & 1.39 & 1.48 \\
1.49 & 1.54 & 1.57 & 1.6 & 1.66 & 1.73 & 1.84 \\
2.03 & 2.08 & 2.13 & 2.17 & 2.25 & 2.36 & 2.51 \\
\hline
\end{tabular}

\section{Beach slope cumulative frequency distribution}

The calculated beach slopes (Table 4) can then be combined with the joint probability values for each group (Table 2) to obtain the desired beach slope frequency distribution, shown in Figure 4 as a cumulative distribution. The 'lumpy' nature of the distribution is a reflection of the number of range groups used in the calculation. A greater number of groups would result in a smoother distribution curve. 


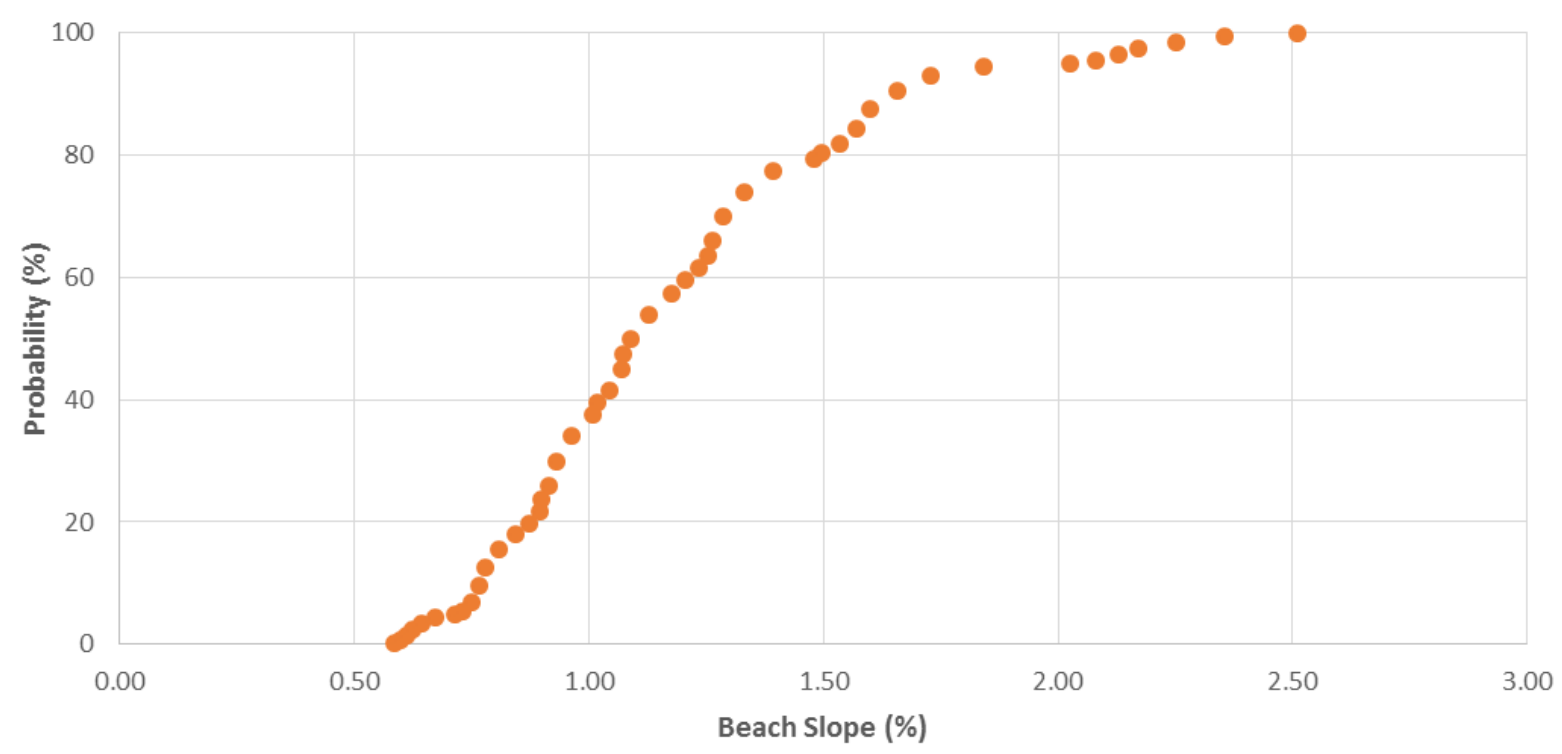

Figure 4 Derived beach slope frequency distribution

The statistical values for this results may be summarised as follows:

Max. slope: $\quad 2.51 \%$.

Min.: $\quad 0.58 \%$.

Average: $\quad 1.24 \%$.

Median: $\quad 1.09 \%$.

It is then possible to enter Figure 4 (from the cumulative frequency axis) with a set of random numbers, and generate a time series for beach slope. An example of this is shown in Figure 5, based on a daily time step.

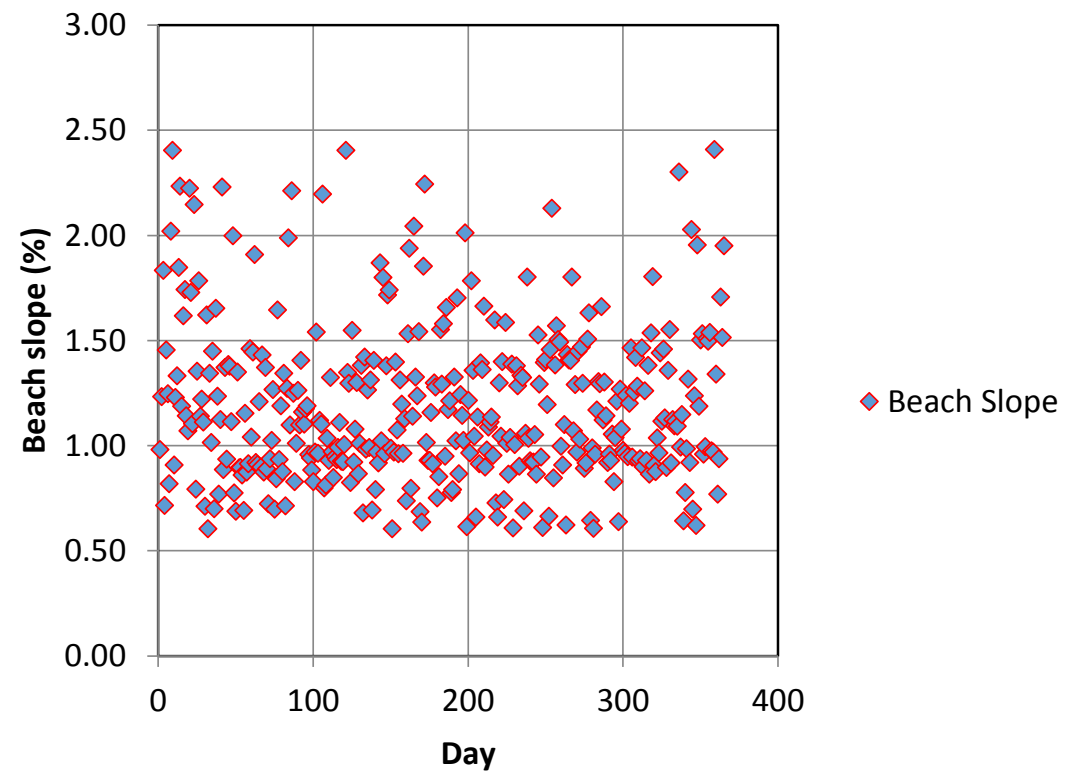

Figure 5 Daily beach slope variation over 365 days 


\section{$7 \quad$ Beach profile modelling}

The beach slope for the example case was modelled on a step-wise basis, using daily beach slope values, similar to the results shown in Figure 5.

The model was set up to run for a central thickened discharge configuration, assuming a horizontal base plane, a single central discharge point, and a daily volumetric requirement of $20,000 \mathrm{~m}^{3} /$ day (Table 1), based on the predicted long-term stack density. Any other configuration of base terrain, and variations in deposition methodology could be accommodated.

The authors have access to depositional software developed 'in-house' which can be utilised for this type of application. However to generalise the outcomes, the commercial program Muck3D (MineBridge Software Inc. n.d.), provided by MineBridge was used. Inputs to the deposition model include discharge point and orientation range, time step, volume to be placed, and deposition angle. For the present example, a single deposition point was set, with a $360^{\circ}$ discharge range, and a daily time step. The program searches for the nearest location that has the capacity to contain the specified volume of tailings, at or below the specified slope angle. The model surface is updated after each increment. For the current version of this program it is necessary to enter the beach slope values for each day manually, but it is understood the proprietors are working on a modification to avoid this. This procedure is somewhat time-consuming, as are the run times. Nevertheless, the software successfully modelled beach accumulation over a period of years.

\section{$8 \quad$ Results}

Results for the end of Year two are shown in Figures 6 and 7. The dimensions of the stack at this time are around 2,000 $\mathrm{m}$ in diameter, with a maximum height of about $15 \mathrm{~m}$. It contains $20 \mathrm{Mt}$ of tailings. Figure 6 shows a plan view, including the deposition fans from previous deposition episodes that remains visible on the surface. Figure 7 shows the beach profile in cross section (to an exaggerated scale).

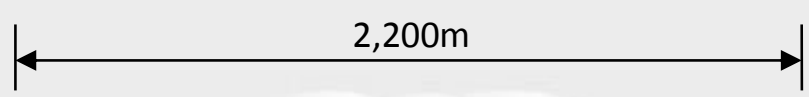

Figure 6 Model of stack at end of Year two 


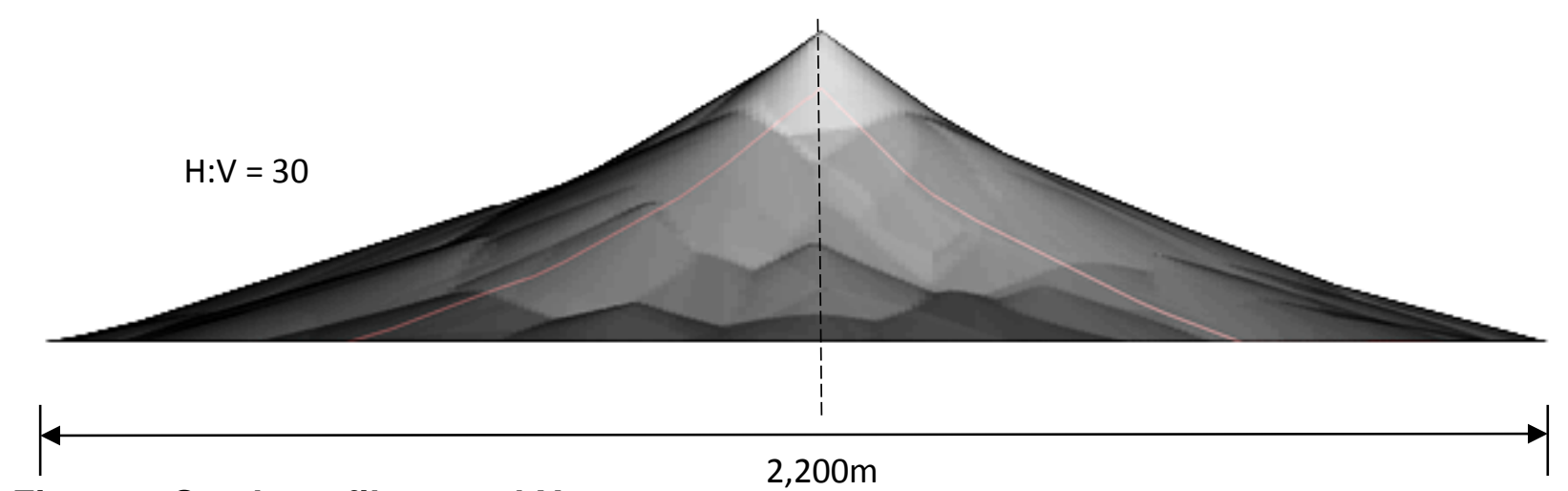

Figure 7 Stack profile at end Year two

\section{Discussion}

There have now been a number of published examples of the beach slopes of thickened tailings stacks, most recently Seddon and Albee (2015). All of these profiles exhibit beach concavity. The methodology proposed in this paper has succeeded in capturing this overall profile.

The actual slope values that attach to this type of profile are considered to be sensitive to a number of input decisions and assumptions:

1. The adopted variability (CV) values for the thickener performance properties. On the basis of available data, the values used in this paper may be considered to be representative of good practice. In a true design case it would be instructive to consider a greater degree of variability (i.e. the $\mathrm{CV}$ values adopted for the thickener performance curves) and evaluate the possible effects of this on the design.

2. The selection of the location representative design points on the performance curves. For the case of mass flow rate, the use of the nominal production rate at the P50 value is probably reasonable. Nevertheless, designers of tailings storages would be advised to understand the full implications of the plant flow sheet and what that means for design tailings production rates.

3. More care and more judgement is required in the case of solids concentration/rheology. It seems clear that following design test-work, manufacturers of thickeners typically give values for the reasonable maximum solids concentration that they believe can be achieved. Under these circumstances it is clearly not appropriate to set this value at P50. This paper has suggested that a better value would be P85, but other points on the curve could be adopted. More data relating the actual performance characteristics of thickeners to the original design values would be of assistance.

Overall, it is recommended that a series of sensitivity analyses should be carried out, particularly for final designs. Wherever possible, contingencies for the worst case scenarios should be incorporated in the operational planning for the storage.

\section{Conclusions}

A method of characterising thickener performance in terms of statistical distributions of underflow solids concentration and mass flow rate has been presented.

These distributions can be combined with existing beach slopes prediction methods to model the progressive build-up of a tailings beach.

The example in this paper is for a central thickened discharge stack on horizontal ground, but the methodology is amenable to other base geometries, and other depositional arrangements.

A sensitivity analysis to evaluate the effect of the values adopted in the design is recommended. 


\section{References}

Fitton, TG, Williams, MPA, Seddon, KD, Bhattacharya, SN, \& Chryss, AG 2007, 'Simulation of thickened tailings stacks', in AB Fourie, \& RJ Jewell (eds), Proceedings of the 10th International Seminar on Paste and Thickened Tailings, Australian Centre for Geomechanics, Perth pp. 305-314.

MineBridge Software Inc. n.d., Muck3D, MineBridge Software Inc., Calgary, www.minebridgesoftware.com/software/muck3d

Pirouz, B, Seddon, KD, Pavissich, C, Williams, P \& Echevarria, J 2013, 'Flow-through tilt flume testing for beach slope evaluation at Chuquicamata Mine, Codelco, Chile', in RJ Jewell, AB Fourie, J Caldwell \& J Pimenta (eds), Proceedings of the 16th International Seminar on Paste and Thickened Tailings, Australian Centre for Geomechanics, Perth, pp. 457-472.

Pirouz, B, Javadi, S, Seddon, K \& Williams, MPA 2014, 'Modified beach slope prediction model for non-segregating thickened tailings', in RJ Jewell, AB Fourie, PS Wells \& D van Zyl (eds), Proceedings of the 17th International Seminar on Paste and Thickened Tailings, InfoMine Inc., Vancouver, pp. 31-46.

Robinsky, El 1999, Thickened tailings disposal in the mining industry, E.I. Robinsky Associates Limited, Toronto.

Seddon, KD \& Albee JK 2015, 'Characterisation of a thickened tailings beach', in RJ Jewell \& AB Fourie (eds) Proceedings of the 18th International Seminar on Paste and Thickened Tailings, Australian Centre for Geomechanics, Perth, pp. 495-506.

Seddon, KD \& Fitton, TG 2011, 'Realistic beach slope prediction and design', in RJ Jewell \& AB Fourie (eds), Proceedings of the 14th International Seminar on Paste and Thickened Tailings, Australian Centre for Geomechanics, Perth, pp. 281-294.

Slatter, PT \& Seddon, KD 2015, 'Evaluation of the rheology of pipe-head flocculated tailings', in RJ Jewell and AB Fourie (eds) Proceedings of the 18th International Seminar on Paste and Thickened Tailings, Australian Centre for Geomechanics, Perth, pp. 131-138. 
Paste 2015 - RJ Jewell and AB Fourie (eds) (C) 2015 Australian Centre for Geomechanics, Perth, ISBN 978-0-9924810-1-8 